\title{
Allergen-induced release of GM-CSF and IL-8 in vitro by nasal polyp tissue from atopic subjects prolongs eosinophil survival
}

\author{
H-S. Park*, K-S. Jung**, J. Shute**, K. Roberts**, S.T. Holgate**, R. Djukanović**
}

Allergen-induced release of GM-CSF and IL-8 in vitro by nasal polyp tissue from atopic subjects prolongs eosinophil survival. H-S. Park, K-S. Jung, J. Shute, K. Roberts, S.T. Holgate, R. Djukanović. CERS Journals Ltd 1997.

ABSTRACT: Eosinophilia is a feature of nasal polyposis. The aim of this study was to determine the role of cytokines and allergen in maintaining the eosinophilic infiltrate in this condition.

Polyp fragments from house dust mite (HDM)-sensitive atopic individuals and nonatopic individuals were cultured in the presence of HDM, or phytohaemagglutinin (PHA) or culture medium alone. Culture supernatants were assayed for interleukins (IL) 3, 5, and 8 and granulocyte macrophage colony stimulating factor (GM-CSF), and eosinophil survival enhancing activity (ESEA) in vitro.

Significant ESEA was produced spontaneously. When polyp tissue from atopics, but not from nonatopics, was stimulated with allergen for 2 days there was a further increase in ESEA associated with a median 12 and fourfold increase in IL-8 and GM-CSF, respectively. This increased ESEA was markedly reduced with antiGM-CSF and, to a lesser extent, anti-IL-8 blocking antibodies. When stimulated with PHA, polyp tissue from atopic subjects also produced increased ESEA, implicating possible T-cell involvement. This was associated with a small (twofold), but significant, increase in IL-8 and a less consistent increase in GM-CSF. However, anti-IL-8 or anti-GM-CSF blocking antibodies failed to reduce the ESEA in these supernatants, suggesting involvement of other mechanisms.

This study suggests that in sensitized individuals, allergen may contribute to polyp eosinophilia by stimulating the production of granulocyte/macrophage colony stimulating factor and interleukin 8.

Eur Respir J 1997, 10: 1476-1482.
*Dept of Allergy and Clinical Immunology, Ajou University Hospital, San-5 Wonchondong, Paldal-gu, Suwon 442-749, Korea. **Immunopharmacology Group, University Medicine, Southampton General Hospital, Southampton, UK.

Correspondence: R. Djukanović

University Medicine

Level D Centre Block

Southampton General Hospital

Southampton

SO16 6YD

UK

\section{Keywords: Cytokines \\ eosinophils}

nasal polyps

\section{Received: June 131996}

Accepted after revision January 241997.

Supported by a British Council Scholarship (HSP and KSJ), the Medical Research Council (UK) and a grant in aid from Pfizer (UK).
Eosinophilia is a characteristic feature of nasal polyps $[1,2]$. Whilst eosinophils play an established role in allergic inflammation, their contribution to the pathogenesis of nasal polyposis is unclear. Their ability to produce vasoactive mediators [3] suggests that they may contribute to oedema formation and, via cytokines such as transforming growth factor (TGF)- $\alpha$ and $\beta$ [4-7], they may promote epithelial proliferation and metaplasia, angiogenesis, matrix generation and tissue remodelling. Eosinophils are also a source of interleukin (IL)-3, IL-4, IL-5, IL-6, IL-8, regulated upon activation normal T-cell expressed and secreted (RANTES), macrophage inflammatory protein-1 $\alpha$ (MIP-1 $\alpha)$, and granulocyte macrophage colony stimulating factor (GM-CSF) [8-15], which have important autocrine effects and modulate the function of other inflammatory cells.

Eosinophilia is usually associated with atopic disease. However, there has been little evidence to suggest that atopy is a risk factor for the development of nasal polyposis $[16,17]$. Nevertheless, a proportion of patients with this condition are atopic, and allergen-driven mechanisms may be involved in this subgroup of patients. Furthermore, the observation that, irrespective of skin test positivity, allergen-specific immunoglobulin E ( $\operatorname{IgE})$ may be detected by radioallergosorbent test (RAST) in homogenized polyp tissue [18], suggests that local specific
IgE-mediated effects may contribute to tissue inflammation. Irrespective of the mechanisms that lead to the development of nasal polyposis, the local environment in the polyps is likely to govern the accumulation of eosinophils. One possible mechanism that may bring this about is the production of cytokines, which upregulate adhesion molecule expression (tumour necrosis factor $\alpha(\mathrm{TNF}-\alpha), \mathrm{IL}-4)[19,20]$, promote the maturation of CD34+ eosinophil progenitors, and prolong the survival of mature eosinophils (IL-3, IL-5 and GM-CSF) $[21,22]$. Potential cellular sources of these cytokines in polyps include epithelial cells [23], fibroblasts [24], eosinophils [4, 12], mast cells [25] macrophages [26], T-cells [27], and endothelial cells [28], although the relative contribution of these cells is unknown.

To improve understanding of mechanisms that underlie the accumulation of eosinophils in nasal polyps we have studied the capacity of polyp tissue in culture to produce IL-3, IL-5 and GM-CSF, cytokines with established effects on eosinophil viability and activation [21]. In addition, we have studied the production by polyp tissue of IL-8, a cytokine that is chemotactic for activated eosinophils (reviewed in [29]) and, in association with secretory immunoglobulin (IgA), induces chemotaxis and activation of eosinophils [30]. By investigating the ability of culture supernatants to prolong the survival 
of eosinophils, and using monoclonal blocking antibodies against the same cytokines, we have sought to identify the principal cytokines that contribute to tissue eosinophilia. In addition to comparing polyps from atopic and nonatopic subjects, we have tested the hypothesis that in sensitized atopic individuals, house dust mite (HDM) (Dermatophagoides pteronyssinus) allergen may contribute to the eosinophilia of nasal polyps.

\section{Materials and methods}

\section{Subjects}

Fourteen subjects undergoing nasal polypectomy for clinical reasons were studied. All had failed to respond to previous treatment with topical corticosteroids. All had failed to improve on corticosteroid treatment, and none had been given any medical treatment for at least 2 months. None had symptomatic infection at the time of surgery. Eight subjects were atopic and six nonatopic, as determined by skin-prick tests to a panel of common aero-allergens (HDM, mixed grass pollens, mixed tree pollens, mixed feathers, cat, dog, horse, aspergillus; ALK, Horsholm, Denmark). All the atopic subjects were sensitive to HDM. None of the nonatopic subjects had immunoglobulin (IgE) levels greater than the upper limit of normal for our laboratory $\left(81 \mathrm{IU} \cdot \mathrm{mL}^{-1}\right)$.

The study was approved by the Ethics Committee of the Southampton University General Hospitals.

\section{Methods}

Nasal polyps were removed surgically and, after washing with RPMI 1640 (Gibco, Paisley, UK), cut into 2 $\mathrm{mm}^{3}$ fragments. To provide cellular correlates for cytokine generation, immunohistochemistry was used to study the extent of cellular infiltration in specimens from the same polyps embedded in glycol methacrylate resin.

Immunohistochemistry. Immunohistochemistry was performed on $2 \mu \mathrm{m}$ sections, as previously described [25], to determine the number of eosinophils containing the cleaved form of eosinophil cationic protein (ECP) (using the murine monoclonal antibody (MoAb); EG2, Pharmacia, Milton Keynes, UK) [31], total T-cells and subsets (using murine MoAbs for CD3+ (Dako, High Wycombe, UK), CD4+ (Becton Dickinson, Abingdon, UK), and CD8+ cells (Dako)). The area of the sections, excluding glands and blood vessels, was calculated using the Video Interactive Display System (VIDS2; Analytical Measurement Systems, Cambridge, UK). The cell counts were expressed as cells $\cdot \mathrm{mm}^{-2}$.

Culture of nasal polyp tissue. Polyp fragments were cultured at $37^{\circ} \mathrm{C}$ in $5 \% \mathrm{CO}_{2}$ for 2 and 7 days in $0.5 \mathrm{~mL}$ of culture medium consisting of RPMI 1640 with $5 \%$ human $\mathrm{AB}$ serum, $2 \mu \mathrm{M}$ mercaptoethanol, $1 \mathrm{mM}$ L-glutamine, $2 \mathrm{mM}$ sodium pyruvate, $100 \mu \mathrm{g} \cdot \mathrm{mL}^{-1}$ streptomycin, $100 \mathrm{U} \cdot \mathrm{mL}^{-1}$ penicillin, and $0.5 \mu \mathrm{g} \cdot \mathrm{mL}^{-1}$ fungizone (complete medium) (all from Gibco). Parallel cultures were set up (one fragment per culture condition) in medium alone or supplemented with $20 \mu \mathrm{g} \cdot \mathrm{mL}^{-1}$ of $D$. pteronyssinus allergen (National Institute for Biological Standards and Control, Potters Bar, UK), as an allergen-specific stimulus, or $2 \mu \mathrm{g} \cdot \mathrm{mL}^{-1}$ of PHA (Sigma, Poole, UK), as a positive control stimulus, to generate control, allergen-conditioned and PHA-conditioned culture supernatants, respectively. After incubation, excess fluid was absorbed on nitrocellulose paper and the tissue weighed. There was no significant difference in weight between the cultured polyp fragments from nonatopic individuals (median weights $7.5 \mathrm{mg}, 8.2 \mathrm{mg}$ and $8.7 \mathrm{mg}$ in control, PHA- and allergen-stimulated cultures respectively) and from atopic individuals (median weights 7.4 $\mathrm{mg}, 9.9 \mathrm{mg}$ and $14.0 \mathrm{mg}$, in control, PHA- and allergen-stimulated cultures, respectively).

The culture supernatants were stored at $-80^{\circ} \mathrm{C}$ until analysis.

Measurement of supernatant IL-3, IL-5, GM-CSF and IL-8 levels. The concentrations of IL-3, IL-5, and GM$\mathrm{CSF}$ in supernatants were determined by enzyme linked immunosorbent assay (ELISA) using commercially available kits (R\&D System, Minneapolis, MN, USA). To measure IL-8, ELISA plates were coated with mouse, immunoglobulin $\mathrm{G}$ (IgG) anti-IL-8 MoAb (donated by I. Lindley, Sandoz, Vienna, Austria) at $4^{\circ} \mathrm{C}$ overnight and washed with $0.05 \%$ Tween-phosphate buffered saline (PBS-T). Ten microlitres of each supernatant, diluted with $90 \mu \mathrm{L}$ of PBS-T/1\% bovine serum albumin, were incubated for $2 \mathrm{~h}$ at $37^{\circ} \mathrm{C}$. This was followed by further incubation with unconjugated goat polyclonal IgG anti-IL-8 antibody (Sigma, Poole, UK) for $2 \mathrm{~h}$ at $37^{\circ} \mathrm{C}$. After blocking with 5\% mouse serum for $2 \mathrm{~h}$, alkalinephosphatase conjugated anti-goat IgG antibody (1:2000 diluted, Sigma, Poole, UK) was incubated for $90 \mathrm{~min}$ at $37^{\circ} \mathrm{C}$. O-phenylenediamine was used as the substrate and the absorbance value read at $410 \mathrm{~nm}$. The concentrations of IL-8 were estimated from a standard curve.

Cytokine concentrations were expressed as $\mathrm{pg} \cdot \mathrm{mL}^{-1}$ supernatant $\cdot \mathrm{mg}^{-1}$ cultured polyp tissue.

Eosinophil survival enhancing activity (ESEA). ESEA was measured as the activity that promoted the survival of peripheral blood eosinophils in 4 day cultures using a modification of a previously described method [22, 32]. Eosinophils were isolated from peripheral blood of mildly atopic, but asymptomatic, donors. Greater than $99 \%$ purity was achieved by negative immunomagnetic selection to remove neutrophils from mixed granulocyte preparations using mouse anti-human CD16 antibody (Eurogenetics, Middlesex, UK) and rat anti-mouse IgG antibody-microbeads (Miltenyi Biotec, Bergisch Gladbach, Germany) [33].

Cultures were set up with $2 \times 10^{5}$ eosinophils in $500 \mu \mathrm{L}$ of culture medium supplemented with $10 \mu \mathrm{L}$ of control supernatants, PHA-conditioned and allergen-conditioned supernatants generated in 2 and 7 day polyp tissue cultures. Preliminary experiments determined that optimum ESEA was achieved with $10 \mu \mathrm{L}$ of conditioned culture supernatant. Media alone or media supplemented with 10 $\mu \mathrm{L}$ of either PHA $\left(2 \mu \mathrm{g} \cdot \mathrm{mL}^{-1}\right)$ or allergen $\left(20 \mu \mathrm{g} \cdot \mathrm{mL}^{-1}\right)$ (control media) were used as controls for baseline ESEA. After 4 days of culture, viability was determined by trypan blue exclusion. The results were expressed as the eosinophil survival index (ESI), which was derived by dividing the percentage of viable eosinophils in cultures containing control or conditioned supernatants by the percentage of viable eosinophils in control media. 
After identifying enhanced ESEA in allergen- and PHAconditioned supernatants, blocking experiments were performed using these and control supernatants and blocking MoAb against IL-3, IL-5, GM-CSF (10 $\mu \mathrm{g}$ in $10 \mu \mathrm{L})$ (provided by Genzyme, Cambridge, MA, USA) and IL$8(5 \mu \mathrm{g}$ in $10 \mu \mathrm{L})$ (Sandoz, Vienna, Austria). Ten microlitres of supernatant (control, PHA-conditioned, and allergenconditioned) were preincubated with $10 \mu \mathrm{L}$ of blocking antibody for $1 \mathrm{~h}$ at $4{ }^{\circ} \mathrm{C}$ and added to the eosinophil cultures to determine the degree of inhibition of ESEA.

All experiments were performed in duplicate and mean values used for analyses.

\section{Statistical analysis}

Between group and within group comparisons were made using the Mann-Whitney $\mathrm{U}$ and Wilcoxon tests, respectively. A p-value of less than 0.05 was considered to be significant.
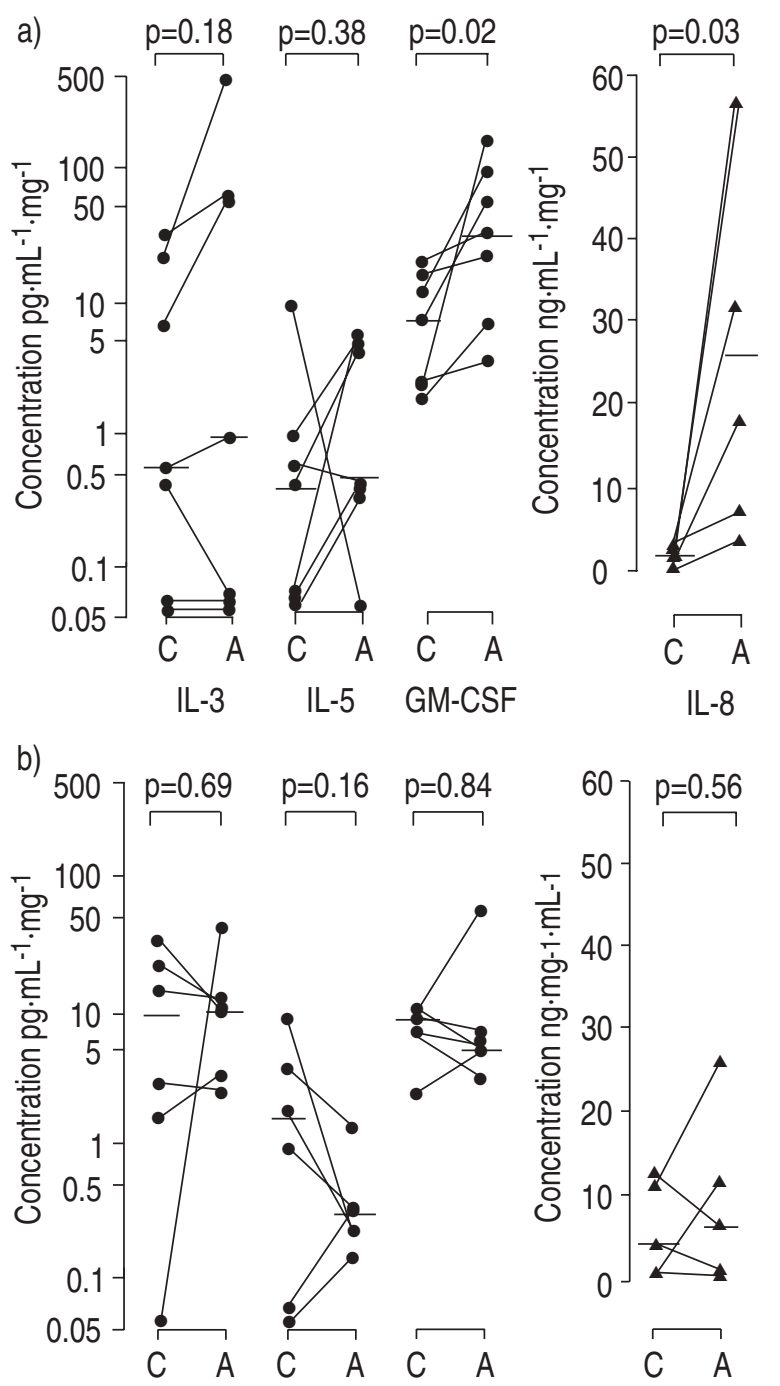

IL-3

IL-5
GM-CSF

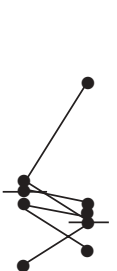

IL-8

\section{Results}

Cell counts in polyp tissue

EG2+ eosinophils were present in all polyps from both atopic (median $23.4 \mathrm{cell} \cdot \mathrm{mm}^{-2}$, range $3.1-78.4$ ) and nonatopic (median 28.9 cells $\cdot \mathrm{mm}^{-2}$, range $1-113.6$ ) subjects, with no significant difference between the two groups. Similarly, the median (range) CD3+, CD4+, and CD8+ cell counts in the atopics $\left(29.5\right.$ cells $\cdot \mathrm{mm}^{-2}(1.3-$ $316.5), 30.0(0-99.1)$, and 17.0 cells $\mathrm{mm}^{-2}(0-431.4)$, respectively) and nonatopics (60.3 cells $\mathrm{mm}^{-2}(1.8-477.4)$, 11.5 cells $\cdot \mathrm{mm}^{-2}(1.4-128.5)$, and 51.6 cells $\cdot \mathrm{mm}^{-2}(8-337.4)$, respectively) were not significantly different.

\section{$I L-3, I L-5, G M-C S F$ and $I L-8$ in supernatants}

Following initial experiments to establish the approximate concentration range and, therefore, the appropriate dilution of the supernatant in which to measure the cytokines, sufficient supernatant was available for the cytokine measurements shown in figure 1.
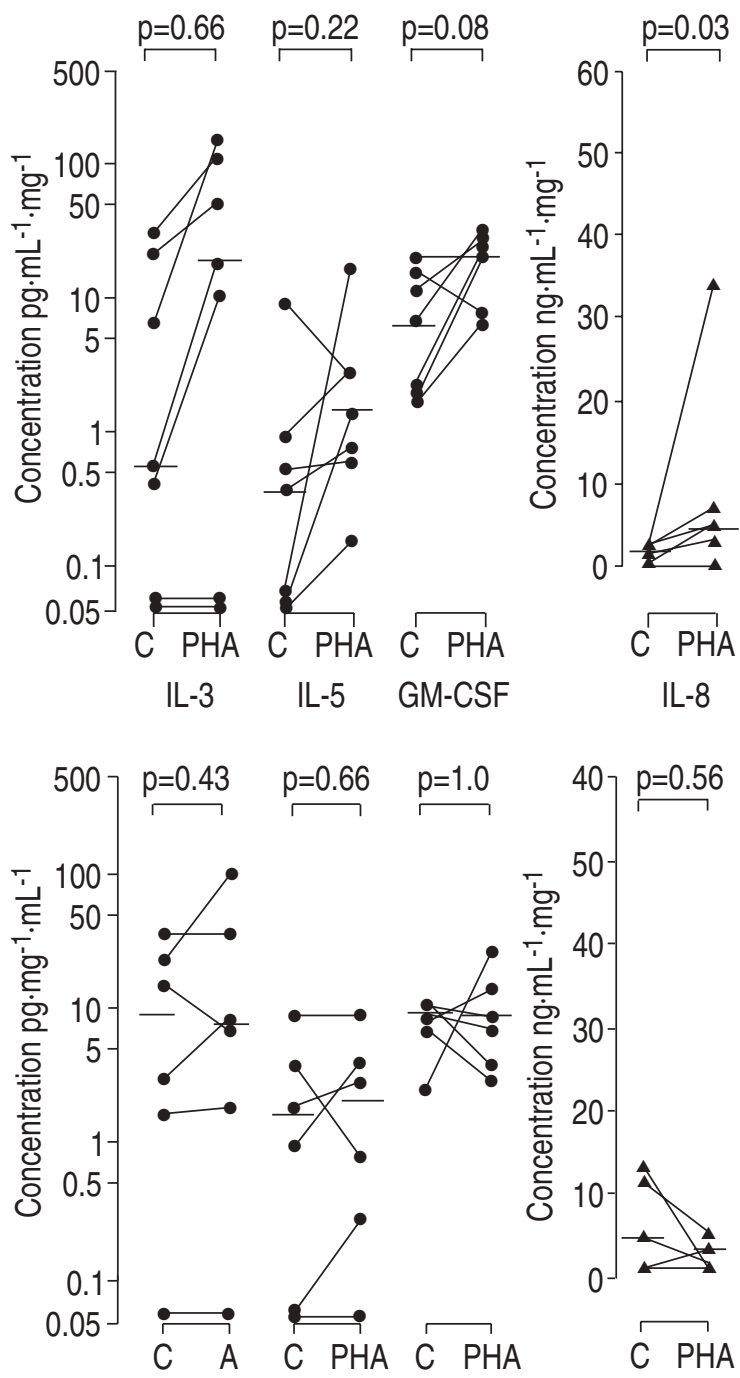

IL-3 IL-5 GM-CSF
IL-8

Fig. 1. - Concentrations of interleukin (IL)-3, IL-5, granulocyte/macrophage colony stimulating factor (GM-CSF) and IL-8 measured in control culture supernatants (C), and allergen- (A) and phytohaeagglutinin (PHA)-conditioned culture supernatants harvested from 2 day cultures of polyp fragments from: a) atopic; and b) nonatopic subjects. Cytokine levels were determined in seven experiments for IL-3, IL-5, GM-CSF and six for IL-8 in cultures of polyp tissues from atopic donors and in six experiments for IL-3, IL-5, GM-CSF, and five for IL-8 in cultures of polyp tissues from nonatopic donors. Horizontal bars represent the median values. Concentrations are expressed as weight of cytokine per millilitre of supernatant per milligram of cultured polyp tissue. 
Spontaneous cytokine release.

The levels of IL- 8 released after 2 days of culture were three orders of magnitude higher than those of IL3, GM-CSF and IL-5 (fig. 1). IL-3, IL-5 and GM-CSF concentrations were low or undetectable in some cultures of tissue from atopic donors. In cultures of tissues from some of the nonatopics the levels of individual cytokines were higher than in the atopics, although statistical analyses showed that none of the differences were significant.

Cytokine release in stimulated cultures. In cultures of polyp tissue from atopic subjects, stimulation with allergen caused a median fourfold (range 1.3-83 fold) increase in GM-CSF ( $\mathrm{p}=0.02)$ and a median 12 fold (range $1.4-28$ fold) increase in IL-8 $(\mathrm{p}=0.03)$ when compared to control cultures (fig. 1). Allergen had no effect on IL-3 levels, and although IL-5 levels increased in five out of seven experiments, this did not reach significance (fig. 1). Increases in IL-3, GM-CSF and IL-8 concentrations were seen in PHA-conditioned supernatants from atopic subjects; however, only the increase in IL-8 was significant $(\mathrm{p}=0.03)$ (fig. 1$)$. In the nonatopic patients, there were no differences in IL-3, IL-5, IL-8 or GMCSF concentrations between control and either allergenor PHA-conditioned supernatants (fig. 1).

\section{The effect of culture supernatants on eosinophil survival}

Spontaneous ESEA. Baseline eosinophil survival was between 2 and $7 \%$ in control media. The presence of allergen extract or PHA in control media had no effect on viability. Control culture supernatants from both atopic and nonatopic subjects enhanced eosinophil survival (fig. 2), although the median (range) ESI from nonatopic subjects $(3(2.3-9.1))$ was significantly $(\mathrm{p}=0.01)$ higher than that from atopic subjects $(1.6(0.9-3.3))$.

Allergen- and PHA-induced ESEA. By comparison with control culture supernatants, both allergen- and PHAconditioned supernatants of 2 day cultures of polyp tis-

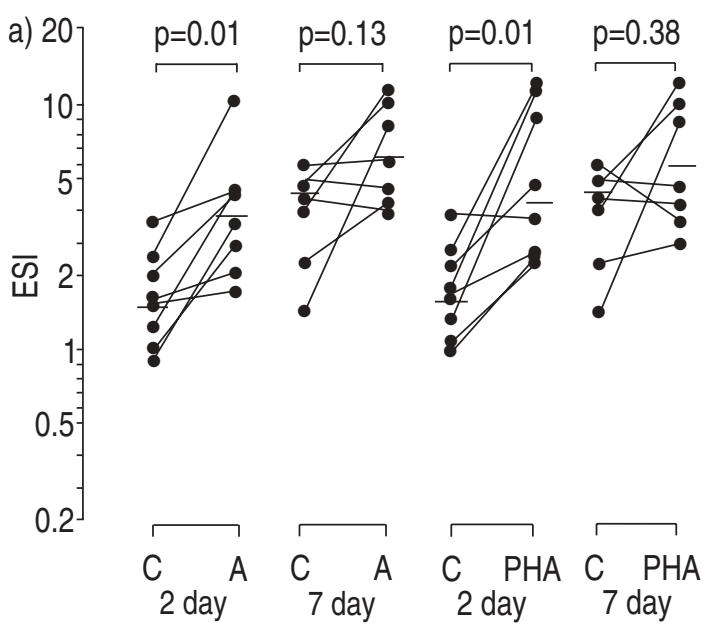

sue from atopic, but not from nonatopic subjects, caused a significant $(\mathrm{p}=0.01)$ increase in ESI to median (range) 3.7 (1.7-10.3) and 3.9 (2.1-11.1), respectively (fig. 2). No increase in ESI was detectable at day 7 in either allergen- or PHA-conditioned supernatants (fig. 2).

The effect of blocking anti-IL-3, -IL-5, -GM-CSF and -IL-8 antibodies on ESEA

The ESEA in control culture supernatants could be suppressed by anti-GM-CSF antibodies, although this failed to reach statistical significance $(p=0.06)$ (fig. 3). The PHA-induced increase in ESEA could not be inhibited to a statistically significant degree by any of the blocking antibodies (fig. 3). However, significant suppression of ESEA in allergen conditioned culture supernatants was achieved with blocking antibodies to GM-CSF

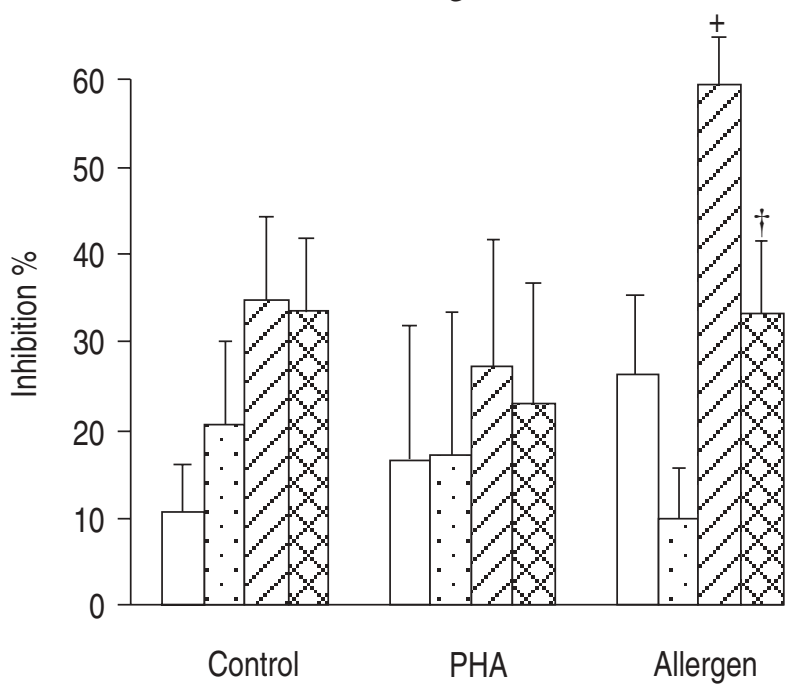

Fig. 3. - Effect of blocking antibodies to IL-3 ( $\square$ ), IL-5 ( $\cdot \cdot$ ), IL-8 ( $)$ and GM-CFS ( $\mathrm{Y}$ ) on eosinophil survival. The degree of inhibition is expressed as percentage inhibition by blocking antibodies of eosinophil survival index measured in the absence of any blocking antibody in the control, phytohaemagglutin (PHA)- and allergen-conditioned supernatants. $+: \mathrm{p}=0.02 ; \dagger: \mathrm{p}=0.03$, versus supernatants without blocking antibodies.

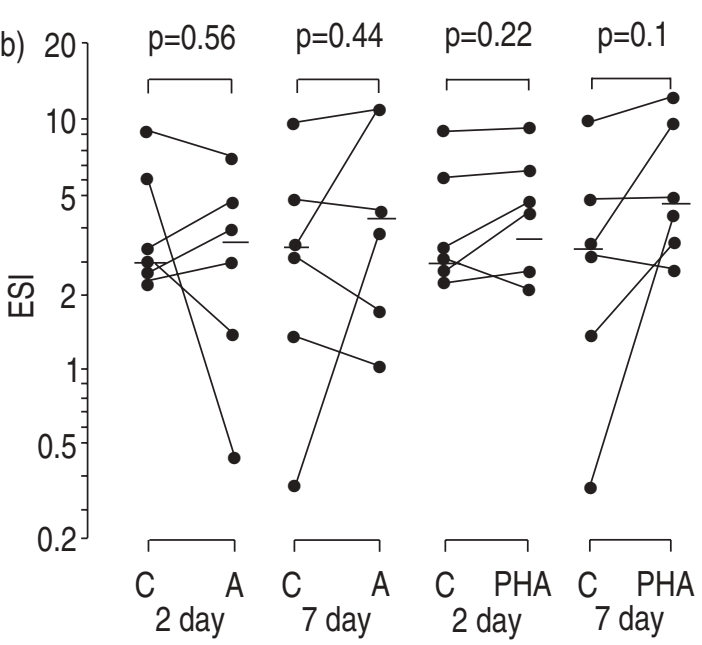

Fig. 2. - Eosinophil survival, expressed as the eosinophil survival index (ESI), in the presence of control (unstimulated) culture supernatants, allergen- and phytohaemagglutinin (PHA)-conditioned supernatants supernatants harvested after 2 and 7 days, from cultures of polyp fragmentss from: a) atopic; and b) nonatopic subjects $(n=8$ and 6 , respectively, except for the 7 day culture of tissue from atopics $(n=7)$. Horizontal bars represent the median values. 
$(\mathrm{p}=0.02)$ and IL-8 $(\mathrm{p}=0.03)$, but not with antibodies to IL-3 and IL-5 (fig. 3). The degree of inhibition by blocking antibodies, expressed as percentage inhibition of ESI measured in the absence of any blocking antibody, was on average $60 \%$ and $33 \%$ for GM-CSF and IL-8, respectively, in the allergen-conditioned supernatants (fig. 3). There were insufficient amounts of supernatant for studies with combined blocking antibodies.

\section{The effect of IL-8 on eosinophil survival}

Following the observation that anti-IL-8 antibodies could decrease the eosinophil survival enhancing effect of allergen-conditioned supernatants, the effect of this cytokine on eosinophil survival was tested using recombinant IL-8 and eosinophils from two atopic donors. Increasing concentrations of IL-8 $(0.001,0.01,0.1,1$ $\left.\mathrm{ug} \cdot \mathrm{mL}^{-1}\right)$ were found to have no effect on eosinophil survival (mean ESI 0.7, 1.3, 0.6 and 0.4, respectively).

\section{Discussion}

We have demonstrated that polyp tissue from both atopic and nonatopic individuals spontaneously generates factors that enhance eosinophil survival, providing one mechanism for eosinophil accumulation in nasal polyps. The presence of ESEA could be detected in culture for up to 7 days, suggesting good viability of the tissue explant and a significant degree of autonomy of local mechanisms that determine eosinophil viability. Although higher levels of spontaneous ESEA were detected in cultures of polyp tissue from nonatopic compared to atopic individuals, further enhancement of ESEA by extracts of HDM allergen could be seen only in the latter. The finding of increased allergen-provoked release of GM-CSF and IL-8, and the ability to attenuate enhanced ESEA with blocking antibodies for GM-CSF, and to a lesser extent IL-8, suggests that these two cytokines are the main contributors to increased eosinophil survival resulting from allergenic stimulation. Taken together these results suggest that, contrary to a widely held view, allergen may play a role, albeit small, in the pathogenesis of nasal polyps.

To date, most studies of mediators generated by nasal polyps have used primary epithelial cell and fibroblast cultures to demonstrate the ability of these two cell types to produce cytokines such as IL-8 [34], TGF- $\beta$ [4] and GM-CSF $[23,35,36]$. Only a minority of studies have used cultures of polyp fragments [12, 37, 38]. Because cultures of isolated cells do not necessarily represent events occurring in whole tissue, we have chosen to culture polyp fragments containing all the structural and inflammatory cells that form a complex cellular network. Some of the advantages of using explants are that biopsies need be taken only once, as they can be challenged ex vivo, there are no problems with dilution factors as is the case with lavage, and production of mediators is restricted to resident cells as opposed to additional contribution from migrating cells. To our knowledge specific allergen has never been used to study cytokine responses by polyp tissue in vitro, although it has been used to induce release of histamine, slow-reacting substance of anaphylaxis A (SRS-A), and eosinophil chemotactic factor A (ECF-A) [38].

As the indication for polypectomy is failure to respond to corticosteroids, we can assume that the underlying pathology of the polyps in previously reported studies was similar to that in our study. Corticosteroids have been shown to significantly attenuate the ESEA present in polyp culture supernatants [39], an effect that can be attributed, at least partially, to inhibition of cytokine generation [34]. To avoid any treatment-related effects, we have ascertained that none of the patients had been treated with either topical or oral corticosteroids for at least 2 months prior to surgery.

The ability of IL-3, IL-5 and GM-CSF to enhance eosinophil survival in vitro is well established. However, the question of their relative importance in vivo has not been addressed. The apparent discrepancy between reported effects of recombinant cytokines in vitro and our own analyses is likely to reflect different activity of cytokines within complex biological fluids. In this study, spontaneous ESEA could be blocked only partially with anti-GM-CSF antibodies, suggesting that, in the experimental conditions employed, spontaneous ESEA was either due to combined effects of the individual cytokines studied or resulted from additional effects of other factors such as RANTES, IL-16 and interferon- $\gamma$. We have shown that the enhancement caused by specific allergen is largely dependent on GM-CSF, in that blocking antibodies could almost completely abrogate the ESEA of allergen-conditioned supernatants. Although the rise in IL-8 following stimulation with allergen was greater than that of GM-CSF, anti-IL-8 antibodies reduced the ESEA by a median of only $30 \%$. IL-8, an alpha (C-XC) chemokine, is associated with a number of inflammatory diseases of the lungs including those associated with eosinophilia $[40,41]$. Whilst its potent effects on neutrophils have been well established, its relationship to eosinophil function has not been appreciated until recently. In atopic subjects, priming of eosinophils with IL-3, IL-4, IL-5 and GM-CSF induces a chemotactic response to IL-8 [29]. Although the use of anti-IL-8 antibodies abrogated the allergen-enhanced eosinophil survival, this was not a direct effect as shown in separate experiments using IL-8 alone. Thus, this cytokine may require tissue-derived co-factors such as proteoglycans [42] or IgA [30] (which we did not measure) in order to be effective in this assay. Alternatively, eosinophils may require additional in vivo priming before responding to IL-8, as suggested in a study by WARRINGA et al. [43] in which peripheral blood eosinophils were found to respond to IL-8 only after bronchial allergen challenge.

Previous reports that spontaneous production of GMCSF is higher in cultures of epithelial cells from nasal polyps compared with those from the normal nasal mucosa suggests their in vivo conditioning in disease [23]. The nature of this upregulation is unclear. The prolonged increase in ESEA observed in our study and the measurable ESEA in primary epithelial cell cultures [35], which require several days to become established, would suggest a significant level of autonomy of the diseased tissue which persists when the tissue is taken from the diseased organ. The higher levels of spontaneously generated ESEA in cultures of polyps from nonatopics and 
a trend towards increased generation of IL-3 and IL-5 suggests a greater inflammatory potential in polyposis that is not associated with atopy. In keeping with previous observations [18], we have found that the composition of the cellular infiltrate in polyps of atopic and nonatopic subjects is similar. Nevertheless, the differences in cytokine responses and effects on ESEA between polyp tissue from atopics and nonatopics suggests that, like asthma, polyposis is not a homogeneous disease, but may be driven by a variety of mechanisms. Although it has been reported that, irrespective of atopy, specific $\operatorname{IgE}$ to this allergen may be detected in homogenized polyps [18], we have not found any evidence that allergen-mediated mechanisms may be contributing to the eosinophilia of nonatopic polyposis.

The cellular source of the cytokines detected in this study and, indeed, any other factors produced in polyp tissue which may have potentiating effects on eosinophil viability, remains to be determined. Several cell types are possible candidates, some, in the case of atopic subjects, possibly acting via surface IgE. The difference between atopic and nonatopic individuals in responses to PHA, a lectin acting on T-cells via the CD3/TCR complex, suggests greater contribution of these cells in atopic individuals, although somewhat higher basal production of both ESEA and cytokines in nonatopics may have masked any potentiating effect of PHA. These differences were observed despite there being no difference in T-cell counts, suggesting that cell activation may be more relevant than cell numbers. In atopics, comparison between allergen- and PHA-conditioned supernatants identifies different profiles of cytokines, and the failure to inhibit ESEA with blocking antibodies to single cytokines suggests a combined effect of two or more cytokines following stimulation with this lectin. Alternatively, the effect of PHA may be indirect, resulting from the generation of fibroblast-derived factors which synergize with GM-CSF [33] or other, as yet unknown, mechanisms.

In conclusion, we have shown that nasal polyp tissue from both atopic and nonatopic patients spontaneously releases factors that prolong eosinophil survival. When challenged with allergen ex vivo, tissue from atopic patients generates additional granulocyte/macrophage colony stimulating factor and interleukin 8 which further increase the capacity of culture supernatants to enhance eosinophil viability, suggesting that common aeroallergens may play a role in the pathogenesis of this common condition. The full extent of the clinical relevance of this observation remains unclear, but it may be that in a proportion of subjects with atopy, allergen stimulation may contribute to polyp eosinophilia. Further investigation is required to elucidate the cellular source of these cytokines that promote eosinophil survival, the mechanisms leading to their release and the mode of action of interleukin 8 .

\section{References}

1. Stoop AE, Vander Heijden HAMD, Biewenga J, Van der Bann S. Eosinophils in nasal polyps and nasal mucosa: An immuno-histochemical study. J Allergy Clin Immunol 1993; 91: 616-622.

2. Jordana M, Dolovich J, Ohno I, Finotto S, Denburg J. Nasal polyposis: a model for chronic inflammation. In:
Busse WW, Holgate ST, eds. Asthma and Rhinitis. Boston, US, Oxford, UK, Blackwell Scientific Publications, 1995; pp.156-166.

3. Hamann KJ. Eosinophil mediators. In: Busse WW, Holgate ST, eds. Asthma and Rhinitis. Boston, US, Oxford, UK, Blackwell Scientific Publications, 1995; pp. 298-327.

4. Elovic A, Wong DTW, Weller PF, Matossian K, Galli SJ. Expression of transforming growth factors- $\alpha$ and $\beta_{1}$ messenger RNA and product by eosinophils in nasal polyps. J Allergy Clin Immunol 1994; 93: 864-869.

5. Derunck R. The physiology of transforming factor- $\alpha$. Adv Cancer Res 1992; 58: 27-52.

6. Bernard JA, Russette ML, Moses HL. The cell biology of transforming growth factor- $\alpha$. Biochem Biophys Acta 1990; 1032: 79-87.

7. Wong DTW, Weller PF, Galli SJ, et al. Human eosinophils express transforming factor- $\alpha$. $J$ Exp Med 1990; 172: 673-681.

8. Kita H, Ohnishi T, Okubo Y, Weiler D, Abram JS, Gleich GJ. Granulocyte/macrophage colony stimulating factor and interleukin 3 release from human peripheral blood eosinophils and neutrophils. J Exp Med 1991; 174: 745-748.

9. Moqbel R, Hamid Q, Ying S, et al. Expression of mRNA and immunoreactivity for the granulocyte/macrophage colony stimulating factor in activated human eosinophils. J Exp Med 1991; 174: 749-752.

10. Descreunaux P, Janin A, Colombel JF, et al. Interleukin 5 messenger RNA expression by eosinophils in the intestinal mucosa of patients with coeliac disease. $J$ Exp Med 1992; 175: 293-296.

11. Hamid Q, Barkans J, Meng Q, et al. Human eosinophil synthesize and secrete interleukin-6 in vitro. Blood 1992; 80: 1496-1501.

12. Ohno I, Lea R, Finotto S, et al. Granulocyte/macrophage colony stimulating factor gene expression by eosinophils in nasal polyposis. Am J Respir Cell Mol Biol 1991; 5: 505-510.

13. Braun RK, Franchini M, Erard F, et al. Human peripheral blood eosinophils produce and release interleukin8 on stimulation with calcium ionophore. Eur J Immunol 1993; 23: 956-960.

14. Ying S, Barata-Taborda L, Meng Q, Humbert M, Kay $\mathrm{AB}$. The kinetics of allergen-induced transcription of messenger RNA for monocyte chemotactic protein-3 (MCP-3) and RANTES in the skin of human atopic subjects: relationship to eosinophil, T-cell and macrophage recruitment. J Exp Med 1995; 181: 2153-2159.

15. Costa JJ, Matossian K, Resnick MB, et al. Human eosinophils can express the cytokines tumour necrosis factor- $\alpha$ and macrophage inflammatory protein- $1 \alpha . J$ Clin Invest 1993; 91: 2673-2684.

16. Slavin RG. Allergy is not a significant cause of nasal polyps. Arch Otolaryngol Head Neck Surg 1992; 118: 343.

17. Caplin I, Haynes TJ, Spahn J. Are nasal polyps an allergic phenomenon? Ann Allergy 1971; 29: 631-634.

18. Liu C-M, Shun C-T, Hsu M-M. Lymphocyte subsets and antigen-specific IgE antibody in nasal polyps. Ann Allergy 1994; 72: 19-24.

19. Osborn L, Hession C, Tizard R, et al. Direct expression and cloning of vascular cell adhesion molecule-1, a cytokine-induced endothelial protein that binds to lymphocytes. Cell 1989; 59: 1203-1211.

20. Schleimer RP, Sterbinsky SA, Kaiser J, et al. IL-4 induces adherence of human eosinophils and basophils but not neutrophils to endothelium. Association with expression of VCAM-1. J Immunol 1992; 148: 1086-1092. 
21. Tai PC, Sun L, Spry CJF. Effects of IL-5, granulocyte/ macrophage colony stimulating factor (GM-CSF) and IL-3 on the survival of human blood eosinophils in vitro. Clin Exp Immunol 1991; 85: 312-316.

22. Rothenberg ME, Owen WF, Siberstein DS, et al. Human eosinophils have prolonged survival, enhanced functional properties and become hypodense when exposed to human interleukin 3. J Clin Invest 1988; 81: 1986-1992.

23. Ohtoshi T, Vancheri C, Cox G, et al. Monocyte-macrophage differentiation induced by human upper airway epithelial cells. Am J Respir Cell Mol Biol 1991; 4: 255-263.

24. Vancheri C, Ohtoshi T, Cox G, et al. Neutrophilic differentiation induced by human upper airway fibroblastderived granulocyte-macrophage colony-stimulating factor (GM-CSF). Am J Respir Cell Mol Biol 1991; 4: 1117.

25. Bradding P, Roberts JA, Britten KM, et al. Interleukin$4,-5$, and tumor necrosis factor- $\alpha$ in normal and asthmatic airway: evidence for the human mast cell as a source of these cytokines. Am J Respir Cell Mol Biol 1994; 10: 471-480.

26. Howell CJ, Pujol JL, Crea AE, et al. Identification of an alveolar macrophage derived activity in bronchial asthma that enhances leukotriene $\mathrm{C} 4$ generation by human eosinophils stimulated by ionophore A23187 as a granulocyte-macrophage colony-stimulating factor. Am Rev Repir Dis 1989; 140: 1340-1347.

27. Corrigan CJ, Kay AB. The lymphocyte in asthma. In: Busse WW, Holgate ST, eds. Asthma and Rhinitis. Blackwell Scientific Publications, Boston, US, Oxford, UK, 1995; 450-464.

28. Ebisawa M, Liu MC, Yamada T, et al. Eosinophil transendothelial migration induced by cytokines. II Potentiation of eosinophil transendothelial migration by eosinophil-active cytokines. J Immunol 1994; 152: 4590-4596.

29. Shute JK. Interleukin-8 is a potent eosinophil chemoattractant. Clin Exp Allergy 1994; 24: 203-206.

30. Shute JK, Lindley I, Peichl P, Holgate ST, Church MK, Djukanovic R. Mucosal IgA is an important moderator of eosinophil responses to tissue-derived chemoattractants. Int Arch Allergy Immunol 1995; 107: 340-341.

31. Tai C-P, Spry CJ, Peterson C, Venge P, Olsson I. Monoclonal antibodies distinguish between storage and secreted forms of eosinophil cationic protein. Nature 1984; 309: 182-184.

32. Owen Jr. WF, Rothenberg ME, Silberstein DS, et al. Regulation of human eosinophil viability, density and function by granulocyte/macrophage colony stimulating factor in the presence of $3 \mathrm{~T} 3$ fibroblasts. $J$ Exp Med 1987; 166: 129-141.

33. Hansel TT, De Vries IJM, Iff T, et al. An improved immunomagnetic procedure for isolation of eosinophils. J Immunol Method 1991; 145: 1-6.

34. Mullol J, Xaubet A, Gaya A, et al. Cytokine gene expression and release from epithelial cells. A comparison study between healthy nasal mucosa and nasal polyps. Clin Exp Allergy 1995; 25: 607-615.

35. Xaubet A, Mullol J, Lopez E, et al. Comparison of the role of nasal polyp and normal nasal mucosal epithelial cells on in vitro eosinophil survival. Mediation by GMCSF and inhibition by dexamethasone. Clin Exp Allergy 1994; 24: 307-317.

36. Xing Z, Ohtoshi T, Ralph P, Gauldie J, Jordana M. Human upper airway structural cell-derived cytokines support human peripheral blood monocyte survival: a potential mechanism for monocyte-macrophage accumulation in the tissue. Am J Respir Cell Mol Biol 1992; 6: 212-218.

37. Furukawa M, Yomashita T, Kumazawa T, Stouchi K, Saito K. Evidence of platelet-activating factor in nasal polyps. ORL J Otorhinolaryngol Relat Spec 1992; 54: 29-32.

38. Kaliner M, Wasserman SI, Austen FK. Immunologic release of chemical mediators from human nasal polyps. N Engl J Med 1973; 289: 277-281.

39. Mullol J, Xaubet A, López E, Roca-Ferrer J, Picado C. Comparative study of the effects of different glucocorticosteroids on eosinophil survival primed by cultured epithelial cell supernatants obtained from nasal mucosa and nasal polyps. Thorax 1995; 50: 270-274.

40. Strieter RM, Standiford TJ, Rolfe MW, Kunkel SL. Interleukin-8. In: Kelley J, ed. Cytokines of the Lung. Lung Biology in Health and Disease. New York, Basel, Hong Kong, Marcel Dekker, 1993; pp. 281-306.

41. Walker C, Bauer W, Braun RK, et al. Activated T-cells and cytokines in bronchoalveolar lavages from patients with various lung diseases associated with eosinophilia. Am J Respir Crit Care Med 1994; 150: 1038-1048.

42. Webb LMC, Ehrengruber MU, Clark-Lewis I, Baggiolini M, Rot A. Binding to heparan sulfate or heparin enhances neutrophil responses to interleukin 8. Proc Natl Acad Sci USA 1993; 90: 7158-7162.

43. Warringa RA, Mengelers HJJ, Raaijmakers JAM, Bruijnzeel PLB, Koenderman L. Upregulation of formyl-peptide and interleukin-induced eosinophil chemotaxis in patients with allergic asthma. J Allergy Clin Immunol 1993; 91: $1198-1205$. 